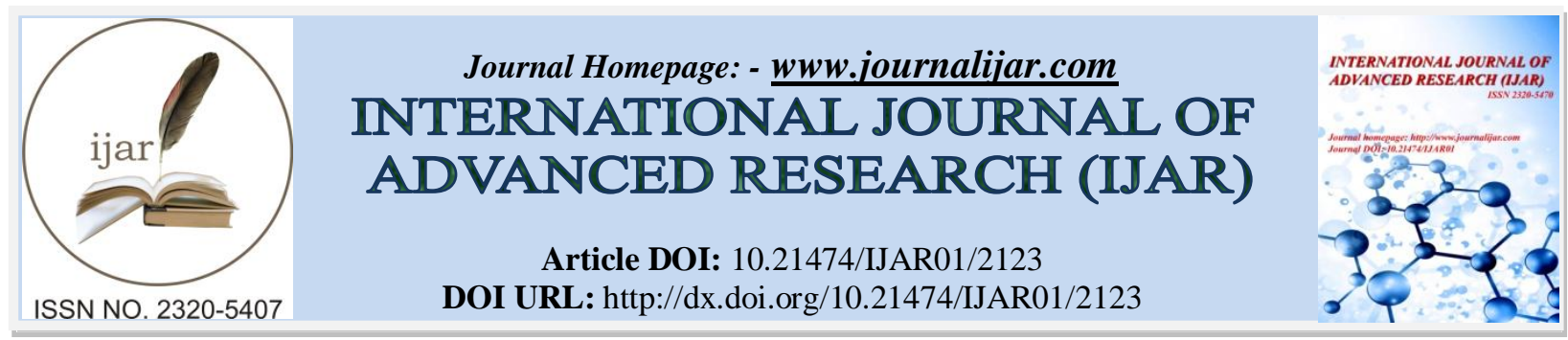

RESEARCH ARTICLE

\title{
A REVIEW ON DIFFERENT COMPUTING METHOD FOR BREAST CANCER DIAGNOSIS USING ARTIFICIAL NEURAL NETWORK AND DATAMINING TECHNIQUES.
}

Radhanath Patra and Shankha Mitra Sunani.

Electronics Department, GIET, Gunupur, Odisha,India.

\section{Manuscript Info}

Manuscript History

Received: 25 September 2016

Final Accepted: 27 October 2016

Published: November 2016

Key words:-

Artificial

neuralnetworks;BreastCancer;ARNN;A

RT;MLP;PNN;LVQ;RBF;GRNN;SVM;

ARNN;WBCD;

\section{Abstract}

Breast Cancer is one of the fatal diseases causing more number of deaths in women. . It is known as one of the most common cancers to afflict the female population. The help of technology such as data mining and machine learning can substantially improve the diagnosis accuracy. Artificial neural networks and data mining have featured in a wide range of medical fields .It has been widely used in intelligent breast cancer diagnosis. The aim of our study is to propose an approach for breast cancer distinguishing between different classes of breast cancer. This approach is based on the Wisconsin Diagnostic Breast Cancer and the classification of different types of breast cancer datasets. Breast cancer diagnosis has been approached by various machine learning and data mining techniques for many years. Artificial Neural Networks in most of the instances gives accurate results for the diagnosis of breast cancer and their use can also be extended to other diseases. Knowledge Discovery in Databases (KDD), which includes data mining classification techniques, is a popular research tool mostly for medical researchers to identify and exploit patterns and relationships among large number of variables, and made them able to predict the outcome of a disease using the historical cases stored within datasets. This paper presents a review on classification of Breast cancer using artificial neural network and various data mining classification techniques. Different techniques are used for the diagnosis and prognosis of breast cancer using artificial neural network data mining classification technique. The models were used namely multilayer perceptron (MLP) using back-propagation algorithm, probabilistic neural networks (PNN), learning vector quantization (LVQ), radial basis network (RBF), general regression neural network(GRNN), support vector machine (SVM), Adaptive Resonance Neural Networks (ARNN), ART, and Feed Forward Artificial Neural Networks and likewise in data mining .The performance of the network is evaluated using Wisconsin breast cancer data set for various training algorithm based on resulted accuracy. This survey can also help us to know about number of papers that are implemented to diagnose the breast cancer. 


\section{Introduction:-}

Cancer is a big threat to human life. Based on statistics from the World Health Organization (WHO), deaths caused by cancer will reach about 12 million people in 2030.Breast cancer has become the leading cause of death in women in developed countries. There are two types of breast lesions- malignant and benign. The Radiologists study various features to distinguish between the malignant tumor and benign tumor. The objective of these predictions is to assign patients to either a"benign" group that is noncancerous or a"malignant" group that is cancerous. Early diagnosis requires an accurate and reliable diagnosis procedure that allows physicians to distinguish benign breast tumors from malignant ones. Thus, it is very important to finding an accurate and effective diagnosis method. In recent years different methods have been widely used in prediction, especially in medical diagnosis. In medical application medical diagnosis is one of major problem. Several research groups are working world wide on the development of neural networks in medical diagnosis. Neural networks are used to increase the accuracy and objectivity of medical diagnosis. Artificial neural networks (ANNs) and data mining techniques have been recently proposed as a very effective method for diagnosis of breast cancer. This paper summarizes the application of artificial neural network and various methods of data mining for detecting breast cancer in human. The remainder of this paper is organized as follows. Section 1.1 and 1.2 describes the framework architecture of neural network and brief summary of data mining process and Section 2 describes literature review based on Artificial Neural Network $(\mathrm{ANN})$ and data mining tools. Here in section 3 provides a conclusion of neural network approaches and data mining methods to breast cancer diagnosis.

\section{Artificial Neural Networks:-}

Neural networks and fuzzy logic are two approaches that are widely used to solve classification and pattern recognition problems. The main advantage of neural networks is their learning Capabilities and their ease of implementation. Artificial neural networks are also referred to as neural nets artificial neural system, parallel distributed processing systems and connectionist systems. The basic processing elements of neural networks are called artificial neurons, or simply neurons or nodes. In a simplified mathematical model of the neuron, the effects of the synapses are represented by connection weights that modulate the effect of the associated input signals, and the nonlinear characteristic exhibited by neurons is represented by a transfer function. It is necessary for the system to have a labeled directed graph structure where nodes perform some simple computations. From elementary graph theory we recall that a directed graph consists of a set of nodes (vertices) and a set of connections (edges/links/arcs) connecting pairs of nodes. A graph is a labeled graph if each connection is associated with a label to identify some property of the connection.



(a) Artificial neuron

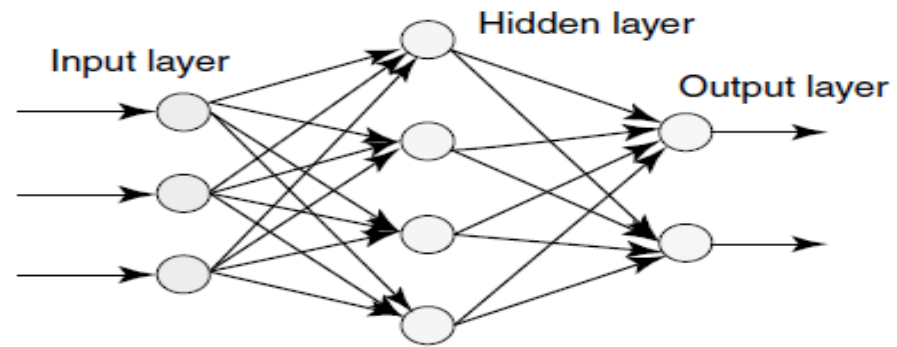

(b)

Multilayered artificial neural network

Figure 1:- Architecture of an Artificial Neuron and a Multilayered Neural Network

\section{Data Mining:-}

Data mining is a part of Knowledge Discovery database (KDD) which is an emerging field in recent research for medical diagnosis and prognosis purpose. Data mining process uses data analysis method such as statistics, machine learning and artificial intelligence to attain new non-trivial knowledge, e.g. prediction values, hidden patterns, and dependencies. The aim of DM is extracting new knowledge and deeper insight into a given dataset (often a largescale dataset), which may continue to be used for decision making. Depending on their purpose of application, DM methods are divided into two groups: methods for prediction and methods for data characterization. Characterization tasks are aimed at finding patterns and associations, while prediction tasks are meant to predict certain events or certain unknown values within the relevant sphere of interests. The main methodological difference is that prediction requires a specific variable (class) to be included into the primary data. The solution can be numeric or categorical; respectively, DM methods for prediction are divided into regression and classification. DM methods can 
be divided into three main categories: supervised learning technique; unsupervised learning technique; other. The first category of "supervised learning technique" includes the tasks of classification and prediction. The second category of "unsupervised learning technique" is assigned to the tasks of clustering and association rules mining. Visualization, outlier detection and link analysis are not classified as "supervised learning technique" or "unsupervised learning technique". A list of the most popular DM methods and techniques according to a survey conducted by KD Nuggets (Piatetsky-Shapiro, 2014) is as follows: decision trees and decision rules (classification); regression; clustering; descriptive statistics; visualization; link analysis; sequence mining; neural networks (classification); support vector machine; Bayes classification and linear genetic programming. Solving DM tasks includes the selection of appropriate algorithms. Both the selection of DM method and algorithm, and parameterization of the optimal algorithm shall depend on the task objectives of the analysis and characteristics of the available data. The most popular DM tasks and methods applied to the medical domain included classification methods: decision trees, neural networks, decision rules, SVM; clustering methods: k-means and hierarchical clustering; association mining and genetic algorithm.

\section{Literature Review:-}

Literature review reveals that different methods used for diagnosis of breast cancer by using artificial neural networks and data mining approaches particularly in medical system. For the sake of comparison, it is very difficult to get a result as of which system is better one as it depends upon many factors like number of cases to be examined, type of abnormalities and database being used.

In 2010, Dr. K. Usha Rani applied a method of parallel approach by using neural network technique for better classification of diagnosis of breast cancer. The author discussed a variety of different parallelization strategies which have been considered for Artificial Neural Networks like Exemplar Parallelism (EP), Block parallelism, Neuron Parallelism. The experiment in this paper was conducted by considering the single and multi layer neural network models. Back propagation algorithm with momentum and variable learning rate was used to train the networks and MLP was adopted to produce an accuracy of 92\% [5].

In 2010, L. Álvarez Menéndez introduced a SOM based clustering algorithm and examined the polynomial kernel of Support Vector Machines (SVM) in actual clinical diagnosis of breast cancer. This work indicated that SVM can be effectively used for breast cancer diagnosis to help oncologists in order to decide which women should participate in a screening programme and which should not ,In which $100 \%$ of the patients with a high probability of suffering the disease will be identified correctly. In addition over the $64 \%$ of the patients with low possibilities of suffering from the disease will also be identified correctly[33]

In 2012, Seema Singh, Sunita Saini, Mandeep Singh discussed the clustering technique to detect that whether patient's cancer stage is malignant or benign. This paper presented a model Adaptive Resonance Neural Networks (ARNN) specially ART2 models of neural networks for clustering. Here the ART2 used for classification of benign and malignant separately in respective cluster with a overall performance of 82.64\%[11].

In 2012, Ali Raad, Ali Kalakech,Mohammad Ayache discussed the classification of different types of breast cancer (benign and malignant) on Wisconsin Diagnostic datasets using neural network approach, especially multi layer perceptron MLP and the radial basis function RBF. A comparison of MLP and Radial basis function (RBF), in this paper resulted that the RBF technique seems an efficient method for classification in medical applications and especially for the breast cancer classification.RBF network gave 97\% efficiency whereas MLP network having 88\% efficiency, for that author suggested that RBF network performed better than the MLP network. So the supervised technique RBF can be considered a successful model for the detection and classification of various breast cancers[14].

In 2012, Bekaddour Fatima proposed a knowledge extraction and classification of breast cancer disease using basically a Neuro-Fuzzy approach for system design. In this paper the author discussed the diagnosis of the breast cancer using the ANFIS approaches (Adaptive Neuro Fuzzy Inference System). This article dealt with most used algorithm for Performances of the Neuro-Fuzzy systems known as hybrid and back-propagation algorithms. The hybrid methods which combined back-propagation and least squares for learning produced better results than back propagation method and the confusion matrix showing the classification results of the ANFIS model of $98 \%$ accuracy [10]. 
In 2012 Sonia Narang, Harsh K Verma, Uday Sachdev reported a systematic review on breast cancer using adaptive resonance neural networks (ARNN), ART and feed forward artificial neural networks. Here the author highlighted the performance of the network using ART Model, a diagnostics system that performs at accuracy [9].

In 2012, Yasmeen M. George, Bassant Mohamed Elbagoury, Hala H. Zayed and Mohamed I. Roushdy proposed an intelligent diagnosis system for breast cancer classification. For this purpose the author discussed the Artificial Neural Networks and Support Vector Machines to classify the benign and malignant and used Four classification models namely multilayer perceptron (MLP) using back-propagation algorithm, probabilistic neural networks (PNN), learning vector quantization (LVQ) and support vector machine (SVM).In this paper the author developed computer-aided diagnosis system for breast classification with feature extraction process from image segmentation and applied the different machine learning algorithm on Six data models and predicted that PNN and SVM were used to produce the efficiency of $99.7 \%$ in terms of sensitivity and accuracy[13].

In 2013, Ali KELES, Ayt" urk KELES preferred on strong diagnostic fuzzy rules for the inference engine of an expert system to be used for breast cancer diagnosis by using a neuro-fuzzy classification tool called NEFCLASS to extract strong diagnosis. To create this model, the "Mammographic Mass" dataset taken from the University of California - Irvine (UCI) Machine Learning Repository was used. The learning algorithm of this tool was heuristic and it had efficient performance diagnosis and classification tasks. The rule base to be used for diagnosis consists of 9 rules using the Breast Imaging Reporting and Data System (BI-RADS), this paper focused on developing a model to diagnose breast cancer because it was quite difficult to distinguish between benign and malignant mammographic findings. For this, the neuro-fuzzy method was used, which has given the best results in medical implementations. To design interference engine a new system was developed called Ex-DBC which is a strong diagnostic tool for the diagnosis of breast cancer with a negative predictive value of $93 \%$ [18].

In 2014, Chandra Prasetyo Utomo, Aan Kardiana, Rika Yuliwulandari implemented artificial neural network for diagnosing breast cancer based on Breast Cancer Wisconsin Dataset. In this paper the author used extreme learning techniques and the results showed that Extreme Learning Machine Neural Networks (ELM ANN) has better generalization classifier model than Back Propagation Artificial Neural Networks (BP ANN).Here the performance of ELMANN technique compared with BPANN which was based on learning algorithm. This paper showed a result ELM ANN has better performances in term of sensitivity and accuracy in all experiments and with accuracy of more than $95 \%$ [22].

In 2014, Seema Singh, Sushmitha H, Harini J and Surabhi B.R, proposed an automated technique using a multilayer Feed Forward network using Back Propagation algorithm is used to classify the WDBC Dataset. In this paper the author used scaled conjugate gradient (SCG) and Bayesian regularization (BR) to predict the accuracy and result with SCG for WBCD was $97.51 \%$ of accuracy [21].

In 2014,J. Dheeba , N. Albert Singh , S. Tamil Selvi represented a new classification approach for detection of breast abnormalities in digital mammograms using Particle Swarm Optimized Wavelet Neural Network (PSOWNN). The proposed abnormality detection algorithm was useful in order to process feature extraction from mammograms of 54 patients with WNN.The result showed that the area under the ROC curve of the proposed algorithm is 0.96853 with a sensitivity $94.167 \%$ of and specificity of $92.105 \%$ with accuracy of $93.167 \%$. The misclassification rate was found to be 0.063291 which is less as compared with the classification done by other classifiers [25].

In 2014, R.Pavitha, Ms T.Joyce Selva Hephzibah proposed a automatic support system for classification of breast cancer .It introduced image processing on mammographic images with feature extraction and use of PNN to classify in faster and accurate manner for predicting cancerous or noncancerous data [30].

In 2014,G.Lavanya, R.Sree Padmini Proposed a method on PNN and RBFNN for prediction of breast cancer on mammographic data and the accuracy obtained here is $91.66 \%$ and $93.33 \%$ respectively[28].

In 2015 Htet thazin tike thein and khin mo mo jun applied a Island differential algorithm with feed forward neural network in java platform considering WBCD with the help of random migration topology to achieve the accuracy of $99.97 \%$ with minimum time span[31]. 


\begin{tabular}{|c|c|c|c|c|c|c|}
\hline $\begin{array}{l}\text { SL.N } \\
\text { O }\end{array}$ & $\begin{array}{l}\text { YEA } \\
\mathrm{R}\end{array}$ & AUTHOR & TOPIC & $\begin{array}{l}\text { ALGOROTHIM/TECHNI } \\
\text { QUES }\end{array}$ & ATTRIBUTES & $\begin{array}{l}\text { ACCURA } \\
\text { CY }\end{array}$ \\
\hline 1 & 2010 & $\begin{array}{l}\text { Dr. K. Usha Rani } \\
\text { and } \\
\text { Padmavathi } \\
\text { Mahila } \\
\text { isvavidyalayam }\end{array}$ & $\begin{array}{l}\text { Parallel } \\
\text { approach for } \\
\text { diagnosis of } \\
\text { breast } \\
\text { cancer } \\
\text { Using } \\
\text { neural } \\
\text { network } \\
\text { technique[5] }\end{array}$ & MLP & $\begin{array}{l}\text { WBCD(11attribu } \\
\text { tes) }\end{array}$ & $92 \%$ \\
\hline 2 & 2012 & $\begin{array}{l}\text { Sonianarang, } \\
\text { harsh kverma, } \\
\text { uday }\end{array}$ & $\begin{array}{l}\text { A Review } \\
\text { Of Breast } \\
\text { Cancer } \\
\text { Detection } \\
\text { Using Art } \\
\text { Model Of } \\
\text { Neural } \\
\text { Networks[9] }\end{array}$ & ART and ANN & WBCD & REVIEW \\
\hline 3 & 2012 & $\begin{array}{l}\text { Ali raad, ali } \\
\text { kalakech,moham } \\
\text { mad ayache }\end{array}$ & $\begin{array}{l}\text { Breast } \\
\text { Cancer } \\
\text { Classificatio } \\
\text { n Using } \\
\text { Neural } \\
\text { Network } \\
\text { Approach: } \\
\text { MLP and } \\
\text { RBF[14] }\end{array}$ & $\mathrm{RBF}$ & WBCD & $97 \%$ \\
\hline 4 & 2012 & $\begin{array}{l}\text { Yasmeen } \quad \mathrm{m} . \\
\text { George }\end{array}$ & $\begin{array}{l}\text { Breast Fine } \\
\text { Needle } \\
\text { Tumor } \\
\text { Classificatio } \\
\text { n using } \\
\text { Neural } \\
\text { Networks[3 } \\
\text { 3] }\end{array}$ & SVM & WBCD & $99.7 \%$ \\
\hline 5 & 2013 & $\begin{array}{l}\text { Ali keles, ayt"urk } \\
\text { keles }\end{array}$ & $\begin{array}{l}\text { Extracting } \\
\text { Fuzzy Rules } \\
\text { For The } \\
\text { Diagnosis } \\
\text { Of Breast } \\
\text { Cancer[18] }\end{array}$ & $\begin{array}{l}\text { Neuro-Fuzzy classification } \\
\text { tool( NEFCLASS) }\end{array}$ & $\begin{array}{ll}\text { Irvine } & \text { (UCI) } \\
\text { Machine } & \\
\text { Learning } & \end{array}$ & $\begin{array}{l}93 \% \text { of } \\
\text { negative } \\
\text { predicted } \\
\text { value }\end{array}$ \\
\hline 6 & 2014 & $\begin{array}{l}\text { Chandra prasetyo } \\
\text { utomo, } \\
\text { aankardiana, rika } \\
\text { yuliwulandari }\end{array}$ & $\begin{array}{l}\text { Breast } \\
\text { Cancer } \\
\text { Diagnosis } \\
\text { using } \\
\text { Artificial } \\
\text { Neural } \\
\text { Networks } \\
\text { with } \\
\text { Extreme } \\
\text { Learning } \\
\text { Technique[2 } \\
\text { 2] }\end{array}$ & $\begin{array}{l}\text { Extreme Learning Machine } \\
\text { Neural Networks }\end{array}$ & WBCD & $95 \%$ \\
\hline 7 & 2014 & $\begin{array}{ll}\text { Seema } & \text { singh, }\end{array}$ & Cancer & SOM and LVQ & WBCD & $97 \%$ \\
\hline
\end{tabular}




\begin{tabular}{|c|c|c|c|c|c|c|}
\hline & & $\begin{array}{l}\text { sushmitha h, } \\
\text { harini j and } \\
\text { surabhi b.r }\end{array}$ & $\begin{array}{l}\text { Detection } \\
\text { By Using } \\
\text { Artificial } \\
\text { Network[21 } \\
\text { ] }\end{array}$ & & & \\
\hline 8 & 2014 & $\begin{array}{l}\text { J. Dheeba , n. } \\
\text { Albert singh } \\
\text { Tamil selvi }\end{array}$ & $\begin{array}{l}\text { Computer- } \\
\text { aided } \\
\text { detection of } \\
\text { breast } \\
\text { cancer on } \\
\text { mammogra } \\
\text { ms: a swarm } \\
\text { Intelligence } \\
\text { optimized } \\
\text { wavelet } \\
\text { neural } \\
\text { network } \\
\text { approach[25 } \\
\text { ] }\end{array}$ & $\begin{array}{l}\text { particle } \\
\text { swarm optimized wavelet } \\
\text { neural network (PSOWNN) } \\
\text { learning rate and } \\
\text { momentum constant set as } \\
0.01 \text { and } \\
0.9\end{array}$ & $\begin{array}{l}25 \text { item features } \\
\text { are extracted }\end{array}$ & $93.671 \%$ \\
\hline 9 & 2014 & $\begin{array}{l}\text { Abdulmajid, } \\
\text { Safdarali, } \\
\text { Mubashariqbal, } \\
\text { Nabeela kausar }\end{array}$ & $\begin{array}{l}\text { Prediction } \\
\text { Of Human } \\
\text { Breast And } \\
\text { Colon } \\
\text { Cancers } \\
\text { From } \\
\text { Imbalanced } \\
\text { Data Using } \\
\text { Nearest } \\
\text { Neighbor } \\
\text { And } \\
\text { Support } \\
\text { Vector } \\
\text { Machines[2 } \\
\text { 6] }\end{array}$ & $\begin{array}{l}\text { MTD-SVM and MTD- } \\
\text { KNN prediction models }\end{array}$ & $\begin{array}{l}13,023 \text { genes in } \\
11 \text { breast }\end{array}$ & $95.18 \%$ \\
\hline 10 & 2014 & $\begin{array}{l}\text { G.Lavanya,R.sree } \\
\text { Padmini }\end{array}$ & $\begin{array}{l}\text { Classificatio } \\
\mathrm{n} \text { Of Breast } \\
\text { Tumor Mass } \\
\text { Using } \\
\text { Probabilistic } \\
\text { Neural } \\
\text { Network } \\
\text { And Radial } \\
\text { Basis } \\
\text { Function } \\
\text { Neural } \\
\text { Network } \\
\text { Algorithm[2 } \\
\text { 8] }\end{array}$ & $\begin{array}{l}\text { Naïve base classifier and } \\
\text { RBFNN Algorithm }\end{array}$ & $\begin{array}{l}\text { tumor based on } \\
\text { mammography } \\
\text { data }\end{array}$ & $\begin{array}{l}\mathrm{NBC}= \\
91.6667 \% \\
\mathrm{RBFF}= \\
93.3333 \%\end{array}$ \\
\hline 11 & 2015 & $\begin{array}{l}\text { Basavaraj } \\
\text { hiremath \& S.C } \\
\text { Prasannakumar }\end{array}$ & $\begin{array}{l}\text { Automated } \\
\text { Evaluation } \\
\text { Of Breast } \\
\text { Cancer } \\
\text { Detection }\end{array}$ & $\begin{array}{l}\text { image } \\
\text { processing morphological } \\
\text { operation+SVM }\end{array}$ & $\begin{array}{l}75 \\
\text { mammographic } \\
\text { images }\end{array}$ & $89.33 \%$ \\
\hline
\end{tabular}




\begin{tabular}{|c|c|c|c|c|c|c|}
\hline & & & $\begin{array}{l}\text { Using SVM } \\
\text { classifier[11 } \\
\text { ] }\end{array}$ & & & \\
\hline 12 & 2015 & $\begin{array}{l}\text { Htet thazin tike } \\
\text { thein and khin mo } \\
\text { mo }\end{array}$ & $\begin{array}{l}\text { An } \\
\text { Approach } \\
\text { For Breast } \\
\text { Cancer } \\
\text { Diagnosis } \\
\text { Classificatio } \\
\text { n Using } \\
\text { Neural } \\
\text { Network[31 } \\
\text { ] }\end{array}$ & $\begin{array}{l}\text { A Island differential } \\
\text { algorithm with feed forward } \\
\text { neural network in java } \\
\text { platform }\end{array}$ & WBCD & $99.97 \%$ \\
\hline
\end{tabular}

In2006, Haowen You and George Rumbe, performed a survey on comparative analysis of different methods of Support Vector Machine, Bayesian classifier and other Artificial neural network classifiers (Back propagation, linear programming, Learning vector quantization, and $\mathrm{K}$ nearest neighborhood) on the Wisconsin breast cancer classification problem .In this paper the author applied statistical learning theory for solving classification and regression problems. The goal of SVM is to determine a suitable hyper plane with maximum margin which can be computed as an optimization problem. Similarly the author applied various learning algorithm employed to the Bayesian network this includes AD (All dimensions) Trees, TAN (Tree Augmented Naïve Bayes) and K2.In this paper training for SVM was conducted by varying a variety of $C$ and gamma ( $\mathrm{\gamma}$ ) values based on 10 fold cross Validation where as for Bayesian network three types Bayesian network i.e., Naïve, K2 and Bayes were examined to determine best network with higher prediction accuracy. Out of these all method SVM gives better accuracy so the SVM has been determined to be more superior to Bayesian network since it provides higher prediction accuracy by comparing the performance of both networks to other neural network approaches[32].

In 2006 Seral Sahana,Kemal Polata, Halife Kodazb, Salih Gune introduced a new method By hybridizing a fuzzy-artificial immune system with $k$-nearest neighbour algorithm ,in order to solve diagnosis problem via classifying Wisconsin Breast Cancer Dataset (WBCD) and classification accuracy of 99.14\% was obtained[2].

In 2006 Sudhir d. Sawarkar,dr,Ashoka.Ghatol have done a survey on Kohonen self-organizing map neural network for classification of breast cancer. For diagnosis the efficiency of self organizing map neural network showed that it can support the doctors or physicians to consider it as a second opinion of the learning machine to prevent biopsy. This method gave more efficiency nearly $98.88 \%$ as compared to SVM method which gives $96.26 \%[1]$.

In 2010,Sarvestan Soltani A, Safavi A, Parandeh M. N. and Salehi M discussed different neural network such as Multilayer Perceptron (MLP), Self Organizing Map(SOM), Radial Basis Function (RBF) and Probabilistic Neural Network(PNN) which are used to classify WBC and NHBCD data and compared all the network according to their accuracy. In this paper the author investigated RBF and PNN were proved as the best classifiers in the training set. But the PNN gave the best classification accuracy when the test set was considered[3].

In 2010, Orlando Anunciacao, Bruno C. Gomes, Susana Vinga, Jorge Gaspar, Arlindo L.Oliveira and Jose Rueff has discussed the applicability of Decision Tree for detection of high-risk breast cancer groups[4].

In 2010, Dr. Medhat Mohamed Ahmed Abdelaal and Muhamed Farouq investigated the capability of the classification SVM with Tree Boost and Tree Forest in analyzing the DDSM dataset. In this paper the author used SVM technique and show promising results for increasing diagnostic accuracy [6].

In 2010, Wei-pin Chang, Der-Ming and Liou, discussed the genetic algorithm which gave better results and better accuracy than other data mining models for the analysis of the data of breast cancer patients. In this paper the author used different method like artificial neural network, decision tree, logistic regression, and genetic algorithm for the comparative studies and the accuracy[12].

In 2011, Shelly Gupta, Dharminder Kumar ,Anand Sharma have done a survey on data mining techniques to enhance the breast cancer diagnosis. In this paper author discussed different commonly used method for data mining classification tasks like Decision Trees (DT’s), Support Vector Machine (SVM), Genetic Algorithms (GAs) / 
Evolutionary Programming (EP), Fuzzy Sets, Neural Networks, Rough Sets and summarized various review and technical articles on breast cancer diagnosis [7].

In 2011 Hui-Ling Chen, Bo Yang, Jie Liu, Da-You Liu proposed a rough set (RS) based supporting vector machine classifier (RS_SVM) .The RS reduction algorithm was employed for features selection followed by SVM(support vector machine)in order to achieve the highest classification accuracies $(99.41 \%, 100 \%$, and $100 \%$ for $50-50 \%$ of training-test partition, $70-30 \%$ of training-test partition, and $80-20 \%$ of training-test partition, Respectively) for a subset that contained five features[8].

.In 2012 Gouda I.Salma , M.B Abdelhalim and Magdy Abd-elghany Zeid performed a comparison among different classifiers such as decision tree, MLP, Naïve Bayes, sequential minimal optimization (SMO) and Instant Based for K nearest nieghbour (IBK) on three different database of breast cancer WBC, WBCD and WPBC with the help of weka tool and predicted the accuracy of $97.2818 \%$ for WBC $97.7153 \%$ for WDBC and $77.3196 \%$ for WPBC dataset respectively[16].

In 2012 Mohammad Fiuzy, Javad Haddadnia, Nasrin Mollania, Maryam Hashemian, Kazem Hassanpour introduced a new algorithm that can detect breast cancer based on combining artificial intelligent system and Fine Needle Aspiration (FNA). Here the study of the Features of Wisconsin Data Base Cancer which contains about 569 FNA test samples (212 patient samples (malignant) and 357 healthy samples (benign)) were studied by combining the Artificial Intelligence Approaches, such as Evolutionary Algorithm (EA) with Genetic Algorithm (GA), and also used Exact Classifier Systems (here by Fuzzy C-Means (FCM)) to separate malignant from benign samples with an accuracy of $96 \%$ [17].

In 2012 Shweta Kharya approached various data mining techniques such as decision tree, associate rule mining ,ANN Naïve Bayes Classifier, Logistic Regression,SVM(support vector machine), Bayesian Networks on breast cancer database and the ultimate conclusion was found that Decision tree is found to be best predictor with 93.62\% Accuracy on benchmark dataset (UCI machine learning dataset)[15].

In 2013 B.M.Gayathri ,C.P.Sumathi and T.Santhanam wrote a survey paper on various diagnosis process of breast cancer by different machine learning process and data mining process with accuracy and emphasized on (RVM)relevance vector machine for diagnosis of breast cancer database[19].

In 2013 Kung-jeng Wnag,Bunjira Makond and Kun Huang Chen and Kung Min Wang proposed a new set of classifier algorithms combination of synthetic minority oversampling technique (SMOTE) and particle swarm optimization (PSO), while integrating some well known classifiers, such as logistic regression,C5 decision tree (C5) model, and 1-nearest neighbor search and analyzed that SMOTE+PSO+C5 gave an accuracy of $94.255 \%$ [24].

In 2013,K.Menaka, S.Karpagavalli made a comparison with support vector machine to that of linear genetic programming on diagnosis of breast cancer in terms of accuracy and finally result was obtained that linear genetic programming was significantly better in both prediction and training time[20].

In 2014 Bichen Zheng, Sang Won Yoon, Sarah S. Lam used a hybrid of K-means and support vector machine (K-SVM) algorithms. The K-means algorithm was utilized to recognize the hidden patterns of the benign and malignant tumors separately and use of machine learning algorithm (SVM) was used to obtain the new classifier to differentiate the incoming tumors. Based on 10-fold cross validation, the proposed methodology improved the accuracy to $97.38 \%$, when tested on the Wisconsin Diagnostic Breast Cancer (WDBC) data set from the University of California -Irvine machine learning repository[23].

In 2014 B.Padmapriya, T.Velmurugan carried out a review work on various data mining classification techniques applied to diagnose breast cancer database.In a survey of review work they got a final conclusion that, among the various classification algorithms ID3, C5.0, ID3, APRIORI, C4.5 and Naïve Bayes in breast cancer analysis,C4.5 is better than the other algorithms[27].

In 2015,Kasra Madadipouya used a a new algorithm based on C4.5 on WBCD (Breast Cancer)which is based on entropy of the attribute and a comparison made with weka tool and result was satisfactory having an accuracy of 97.9\%[29]. 


\begin{tabular}{|c|c|c|c|c|c|c|}
\hline $\begin{array}{l}\text { SL.N } \\
\text { O }\end{array}$ & $\begin{array}{l}\text { YEA } \\
\mathrm{R}\end{array}$ & AUTHOR & TOPIC & $\begin{array}{l}\text { ALGOROTHIM/TECHNIQU } \\
\text { ES }\end{array}$ & $\begin{array}{l}\text { ATTRIBUTE } \\
\mathrm{S}\end{array}$ & $\begin{array}{l}\text { RESULT } \\
\mathrm{S}\end{array}$ \\
\hline 1 & 2006 & $\begin{array}{lr}\text { Haowen } & \text { You } \\
\text { and } & \text { George } \\
\text { Rumbe } & \end{array}$ & $\begin{array}{l}\text { Comparative } \\
\text { Study of } \\
\text { Classification } \\
\text { Techniques on } \\
\text { Breast Cancer } \\
\text { FNA Biopsy } \\
\text { Data[32] }\end{array}$ & 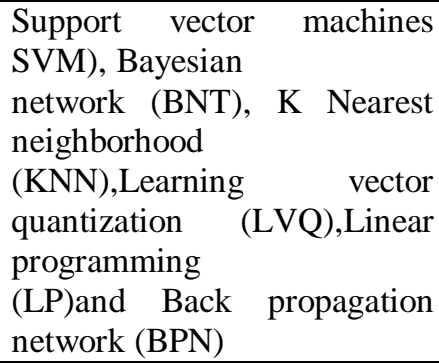 & WBCD & $\begin{array}{l}100 \% \mathrm{FO} \\
\mathrm{R} \mathrm{KNN}\end{array}$ \\
\hline 2 & 2006 & $\begin{array}{l}\text { Seral } \\
\text { Sahan,Kemal } \\
\text { Polat, Halife } \\
\text { Kodaz,Salih } \\
\text { Gune }\end{array}$ & $\begin{array}{l}\text { A new hybrid } \\
\text { method based } \\
\text { on fuzzy- } \\
\text { artificial } \\
\text { immune system } \\
\text { and } k \text {-nn } \\
\text { algorithm for } \\
\text { breast cancer } \\
\text { diagnosis[2] }\end{array}$ & fuzzy-artificial & WBCD & $91.4 \%$ \\
\hline 3 & 2006 & $\begin{array}{lr}\text { Sudhir } & \text { d. } \\
\text { Sawarkar, } & \text { Dr. } \\
\text { Ashok a. Ghatol }\end{array}$ & $\begin{array}{l}\text { Breast Cancer } \\
\text { Malignancy } \\
\text { Identification } \\
\text { using Self- } \\
\text { Organizing } \\
\text { Map[1] }\end{array}$ & SOM & WBCD & $98.88 \%$ \\
\hline 4 & 2010 & $\begin{array}{l}\text { Sarvestan } \\
\text { Soltani A, Safavi } \\
\text { A, Parandeh M. } \\
\text { N. and Salehi M }\end{array}$ & $\begin{array}{l}\text { Predicting } \\
\text { Breast Cancer } \\
\text { Survivability } \\
\text { using Data } \\
\text { Mining } \\
\text { Techniques[3] }\end{array}$ & SOM,MNP,RBF \&PNN & $\begin{array}{l}\text { WBC,NHBC } \\
\text { D }\end{array}$ & $\begin{array}{l}\text { PNN is } \\
\text { better } \\
\text { choice }\end{array}$ \\
\hline 5 & 2010 & $\begin{array}{l}\text { Orlando } \\
\text { Anunciacao, } \\
\text { Bruno } \\
\text { Gomes, Susana } \\
\text { Vinga, Jorge } \\
\text { Gaspar, Arlindo } \\
\text { L.Oliveira and } \\
\text { Jose Rueff }\end{array}$ & $\begin{array}{l}\text { A Data Mining } \\
\text { approach for } \\
\text { detection of } \\
\text { high-risk Breast } \\
\text { Cancer } \\
\text { groups[4] }\end{array}$ & Decision Tree & $\begin{array}{l}\text { Dataset } \\
\text { department of } \\
\text { genetics }\end{array}$ & $\begin{array}{l}\text { Fisher } \\
\text { Exact } \\
\text { Test } \\
\text { value of } \\
9.7 * 10^{6}\end{array}$ \\
\hline 6 & 2010 & $\begin{array}{l}\text { Dr. Medhat } \\
\text { Mohamed } \\
\text { Ahmed Abdelaal } \\
\text { and Muhamed } \\
\text { Farouq }\end{array}$ & $\begin{array}{lr}\text { Using } & \text { data } \\
\text { mining } & \text { for } \\
\text { assessing } & \\
\text { diagnosis } & \text { of } \\
\text { breast cancer[6] }\end{array}$ & SVM & DDSM & $\begin{array}{l}\text { high gain } \\
\text { of svm } \\
\text { with } \\
\text { minimal } \\
\text { error }\end{array}$ \\
\hline 8 & 2011 & $\begin{array}{l}\text { Shelly } \\
\text { Gupta,Dharmind } \\
\text { er Kumar,Anand } \\
\text { Sharma }\end{array}$ & $\begin{array}{l}\text { Mining } \\
\text { Classification } \\
\text { Techniques } \\
\text { Applied For } \\
\text { Breast Cancer } \\
\text { Diagnosis And } \\
\text { Prognosis[7] }\end{array}$ & $\begin{array}{l}\text { DT'S,SVM,GAS, } \\
\text { EP }\end{array}$ & 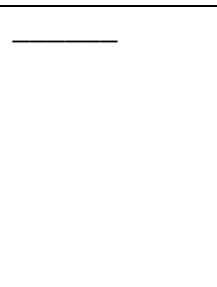 & Review \\
\hline 9 & 2011 & $\begin{array}{l}\text { HUI-Ling Chen, } \\
\text { Bo Yang, Jie Liu }\end{array}$ & $\begin{array}{l}\text { support vector } \\
\text { machine } \\
\text { classifier with }\end{array}$ & RS-SVM & WBCD & $99.41 \%$ \\
\hline
\end{tabular}




\begin{tabular}{|c|c|c|c|c|c|c|}
\hline & & , Da-You Liu & $\begin{array}{l}\text { rough set-based } \\
\text { feature } \\
\text { selection for } \\
\text { breast cancer } \\
\text { diagnosis[8] } \\
\end{array}$ & & & \\
\hline 10 & 2012 & $\begin{array}{l}\text { Gouda I.Salma } \\
\text { M.B Abdelhalim } \\
\text { and Magdy Abd- } \\
\text { elghany Zeid }\end{array}$ & $\begin{array}{l}\text { Breast Cancer } \\
\text { Diagnosis on } \\
\text { Three Different } \\
\text { Datasets Using } \\
\text { Multi- } \\
\text { Classifiers[16] }\end{array}$ & $\begin{array}{l}\text { decision tree, MLP, Naïve } \\
\text { Bayes, sequential minimal } \\
\text { optimization (SMO) and } \\
\text { Instant Based for K nearest } \\
\text { nieghbour (IBK) }\end{array}$ & $\begin{array}{l}\text { WBC,WBCD } \\
\text { and WPBC }\end{array}$ & $\begin{array}{l}97.2818 \\
\% \quad \text { for } \\
\text { WBC } \\
97.7153 \\
\% \quad \text { for } \\
\text { WDBC } \\
\text { and } \\
77.3196 \\
\% \quad \text { for } \\
\text { WPBC }\end{array}$ \\
\hline 11 & 2012 & $\begin{array}{l}\text { Mohammad } \\
\text { Fiuzy, Javad } \\
\text { Haddadnia, } \\
\text { Nasrin Mollania, } \\
\text { Maryam } \\
\text { Hashemian, } \\
\text { Kazem } \\
\text { Hassanpour }\end{array}$ & \begin{tabular}{lr}
\multicolumn{2}{l}{ Introduction of } \\
a New \\
Diagnostic \\
Method for \\
Breast Cancer \\
Based on Fine \\
Needle \\
Aspiration \\
(FNA) Test \\
Data and \\
Combining \\
Intelligent \\
Systems[17]
\end{tabular} & FNA,EA,GA & WBCD & $96 \%$ \\
\hline 12 & 2012 & Shweta Kharya & $\begin{array}{l}\text { Using } \\
\text { Mining } \\
\text { Techniques for } \\
\text { Diagnosis and } \\
\text { Prognosis of } \\
\text { Cancer } \\
\text { Disease[15] } \\
\end{array}$ & $\begin{array}{l}\text { decision tree, associate rule } \\
\text { mining ,ANN Naïve Bayes } \\
\text { Classifier, r Logistic } \\
\text { Regression,SVM(support } \\
\text { vector machine), Bayesian } \\
\text { Networks }\end{array}$ & $\begin{array}{l}\text { UCI machine } \\
\text { learning } \\
\text { dataset }\end{array}$ & 93.62 \\
\hline 13 & 2013 & $\begin{array}{l}\text { B.M.Gayathri } \\
\text {,C.P.Sumathi } \\
\text { and } \\
\text { T.Santhanam }\end{array}$ & $\begin{array}{l}\text { Breast Cancer } \\
\text { Diagnosis } \\
\text { Using Machine } \\
\text { Learning } \\
\text { Algorithms -A } \\
\text { Survey[19] } \\
\end{array}$ & RVM & 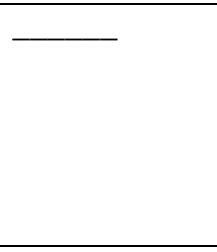 & REVIEW \\
\hline 14 & 2013 & $\begin{array}{l}\text { Kung-jeng } \\
\text { Wnag,Bunjira } \\
\text { Makond and } \\
\text { Kun Huang } \\
\text { Chen and Kung } \\
\text { Min Wang }\end{array}$ & $\begin{array}{l}\text { A hybrid } \\
\text { classifier } \\
\text { combining } \\
\text { SMOTE with } \\
\text { PSO to estimate } \\
\text { 5- } \\
\text { yearsurvivabilit } \\
\text { y of breast } \\
\text { cancer } \\
\text { patients[24] }\end{array}$ & $\begin{array}{l}\text { Synthetic minority } \\
\text { oversampling technique } \\
\text { (SMOTE) and particle swarm } \\
\text { optimization (PSO), C5 } \\
\text { decision tree (C5) model }\end{array}$ & $\begin{array}{l}\text { Seer cancer } \\
\text { database }\end{array}$ & $94.255 \%$ \\
\hline 15 & 2013 & $\begin{array}{l}\text {,K.Menaka, } \\
\text { S.Karpagavalli }\end{array}$ & $\begin{array}{l}\text { Breast Cancer } \\
\text { Classification } \\
\text { using Support } \\
\text { Vector Machine } \\
\text { and Genetic } \\
\end{array}$ & SVM,LGP & WBCD & $\begin{array}{l}99 \% \\
\text { using } \\
\text { LGP }\end{array}$ \\
\hline
\end{tabular}




\begin{tabular}{|l|l|l|l|l|l|l|}
\hline & & & $\begin{array}{l}\text { Programming[2 } \\
\text { 0] }\end{array}$ & & \\
\hline 16 & 2014 & $\begin{array}{l}\text { Bichen Zheng, } \\
\text { Sang Won Yoon } \\
\text { Sarah S. Lam }\end{array}$ & $\begin{array}{l}\text { Breast cancer } \\
\text { diagnosis based } \\
\text { on feature } \\
\text { Extraction } \\
\text { using a hybrid } \\
\text { of K-means and } \\
\text { support vector } \\
\text { machine of K-means and } \\
\text { algorithms[23] } \\
\text { support vector machine (K- } \\
\text { SVM) algorithms }\end{array}$ & WBCD & $97.38 \%$ \\
\hline 17 & 2015 & $\begin{array}{l}\text { A } \\
\text { Decision Tree } \\
\text { Method Foradipouya } \\
\text { Data Mining In } \\
\text { Medicine[29] }\end{array}$ & & C4.5 & WBCD & $97.9 \%$ \\
\hline
\end{tabular}

\section{Conclusion:-}

In the review of diagnosis of breast cancer database, some of following points were much emphasized. Some of the review paper already predicted about the accuracy of different machine learning algorithm .Due to limitation of ANN various modified form of machine learning algorithm as well as hybrid process were adopted to improve accuracy with least time span .some of paper clearly presented that accuracy was above $95 \%$ to $99 \%$. Various data mining process also considered predicting the diagnosis of breast cancer with high accuracy and result showed that decision tree, KNN algorithm and PSO is better in terms of accuracy calculation. Feature extraction with some good algorithm should be carried out with certain modified form of machine learning algorithm or data mining process to a large volume of data in a small time span with much higher accuracy.

\section{Reference:-}

1. Sudhir D. Sawarkar,Dr,Ashok A.Ghatol "Breast Cancer Malignancy Identification using Self-Organizing Map" Proceedings of the 5th WSEAS Int. Conf. on Circuits, Systems, Electronics, Control \& Signal Processing, Dallas, USA, November 1-3, 2006

2. Seral Sahan,Kemal Polat, Halife Kodaz,Salih Gune " A new hybrid method based on fuzzy-artificial immune system and $k$-nn algorithm for breast cancer diagnosis" Computers in Biology and Medicine 37 (2007) 415 423 ELSEVIER

3. Sarvestan Soltani A, Safavi A A, Parandeh M N and Salehi M, "Predicting Breast Cancer Survivability using Data Mining Techniques", Software Technology and Engineering (ICSTE), 2ndInternational Conference, Vol.2, pages 227-231,2010

4. Anunciacao Orlando, Gomes C. Bruno, Vinga Susana, Gaspar Jorge, Oliveira L. rlindo and Rueff Jose, "A Data Mining approach for detection of high-risk Breast Cancer groups", Advances in Soft Computing, Vol. 74, 2010, pp. 43-51

5. Dr. K. Usha Rani "Parallel Approach for Diagnosis of Breast Cancer using Neural Network Technique" International Journal of Computer Applications International Journal of Computer Applications (0975 - 8887), Volume 10- No.3, November 2010

6. Abdelaal Ahmed Mohamed Medhat and Farouq Wael Muhamed, "Using data mining for assessing diagnosis of breast cancer," in Proc. International multiconfrence on computer science and information Technology, 2010, pp. 11-17

7. Shelly Gupta,Dharminder Kumar,Anand Sharma" Data Mining Classification Techniques Applied For Breast Cancer Diagnosis And Prognosis" Indian Journal Of Computer Science And Engineering (IJCSE), Vol. 2 No. 2 Apr-May 2011

8. Hui-Ling Chen,Bo Yang Jie Liu Da-You Liu "A support vector machine classifier with rough set-based feature selection for breast cancer diagnosis"Expert Systems with Applications 38 (2011) 9014-9022, ,ELSEVIER.

9. Sonia Narang, Harsh K Verma, Uday Sachdev "A Review of Breast Cancer Detection using ART Model of Neural Networks" International Journal of Advanced Research in Computer Science and Software Engineering. Volume 2, Issue 10, October 2012 ISSN: 2277 128X. 
10. Bekaddour Fatima, and Chikh Mohammed Amine "A Neuro Fuzzy Inference Model For Breast Cancer Recognition "International Journal of Computer Science \& Information Technology (IJCSIT), International Journal of Computer Science \& Information Technology (IJCSIT) Vol 4, No 5, October 2012

11. Basavaraj Hiremath \& SC Prasannakumar "Automated Evaluation of Breast Cancer Detection Using SVM Classifier"(IJCSEITR) ISSN(P): 2249-6831; ISSN(E): 2249-7943, Vol. 5, Issue 1, Feb 2015, 11-20

12. Seema Singh, Sunita Saini , Mandeep Singh "Cancer detection by using Artificial Network"-International Journal of Advancements in Research \& Technology International Journal of Advancements in Research \& Technology Volume 1, Issue 4, September -2012, ISSN 2278 -7763

13. Chang Pin Wei And Liou Ming Der, "Comparison Of Three Data Mining Techniques With Genetic Algorithm In Analysis Of Breast Cancer Data".[Online]. vailable:Http://Www.Ym.Edu.Tw/ Dmliou/Paper/Compar_Threedata.Pdf

14. Yasmeen M. George, Bassant Mohamed Elbagoury, Hala H. Zayed and Mohamed I. Roushdy ,"Breast Fine Needle Tumor Classification using Neural Networks"-2012- International Journal of Computer Science IJCSI International Journal of Computer Science Issues, Vol. 9, Issue 5, No 2, September 2012

15. Ali Raad, Ali Kalakech ,Mohammad Ayache, "Breast Cancer Classification using Neural Network Approach: MLP AND RBF", the 13th international Arab conference on information technology, ACIT' DEC 2012, 10 13.

16. Shweta Kharya"Using Data Mining Techniques for Diagnosis and Prognosis of Cancer Disease" International Journal of Computer Science, Engineering and Information Technology (IJCSEIT), Vol.2, No.2, April 2012

17. Gouda I. Salama, M.B.Abdelhalim, and Magdy Abd-elghany Zeid" Breast Cancer Diagnosis on Three Different Datasets Using Multi-Classifiers" International Journal of Computer and Information Technology (2277 0764) Volume 01- Issue 01, September 2012

18. Fiuzy M, Haddadnia J, Mollania N, Hashemian M, Hassanpour K. "Introduction of a New Diagnostic Method for Breast Cancer Based on Fine Needle Aspiration (FNA) Test Data and Combining Intelligent Systems". Iran J Cancer Prev. 2012; 5(4):169-77.

19. Ali KELES, Ayt urk KELES " Extracting fuzzy rules for the diagnosis of breast cancer"Turkish Journal of Electrical Engineering \& Computer Sciences, 2013

20. M.Gayathri,C.P.Sumathi,And T.Santhanam"Breast Cancer Diagnosis Using Machine Learning Algorithms -A Survey" International Journal Of Distributed And Parallel Systems (IJDPS) Vol.4, No.3, May 2013

21. K.Menaka, S.Karpagavalli " Breast Cancer Classification using Support Vector Machine and Genetic Programming" International Journal of Innovative Research in Computer and Communication Engineering Vol. 1, Issue 7, September 2013

22. Seema Singh, Sushmitha H, Harini J and Surabhi B.R"An Efficient Neural Network Based System for Diagnosis of Breast Cancer"International Journal of Computer Science and Information Technologies. (IJCSIT) International Journal of Computer Science and Information Technologies, Vol. 5 (3) ,2014, 4354-4360

23. Chandra Prasetyo Utomo, Aan Kardiana, Rika Yuliwulandari" Breast Cancer Diagnosis using Artificial Neural Networks with Extreme Learning Technique"2014 International Journal of Advanced Research in Artificial Intelligence (IJARAI) International Journal of Advanced Research in Artificial Intelligence Vol. 3, No. 7, 2014

24. Bichen Zheng, Sang Won Yoon, Sarah S. Lam "Breast cancer diagnosis based on feature Extraction using a hybrid of K-means and support vector machine algorithms" Expert Systems with Applications 41 (2014) 14761482,ELSEVIER.

25. Kung-Jeng Wanga, Bunjira Makonda,b, Kun-Huang Chena, Kung-Min Wangca "A hybrid classifier combining SMOTE with PSO to estimate 5-yearsurvivability of breast cancer patients", Applied Soft Computing 20 (2014) 15-24,ELSEVIER.

26. J. Dheeba, N. Albert Singh, S. Tamil Selvi "Computer-aided detection of breast cancer on mammograms: A swarm intelligence optimized wavelet neural network approach"Journal of Biomedical Informatics 49 (2014) 45-52,ELSEVIER

27. Abdul Majid, Safdar Ali, Mubashar Iqbal, Nabeela KausarDepartment "Prediction of human breast and colon cancersfrom imbalanced data using nearest neighborand support vector machines"computer method sandprograms

28. in biomedicine113 (201 4 )792-808, ELSEVIER

29. B.Padmapriya, T.Velmurugan" A Survey on Breast Cancer Analysis Using Data Mining Techniques"International Conference on Computational Intelligence and Computing Research,2014

30. G.Lavanya, R.Sree Padmini "Classification of breast tumor mass using probabilistic neural network and Radial basis function neural network algorithm" International Journal of Advanced Scientific and Technical Research Issue 4 volume 2, March-April 2014. 
31. Kasra Madadipouya "A New Decision Tree Method For Data Mining In Medicine" Advanced Computational Intelligence: An International Journal (ACII), Vol.2, No.3, July 2015

32. R.Pavitha1, Ms T.Joyce Selva Hephzibah M.Tech.2 "Mammographic Cancer Detection and Classification Using"

33. Bi Clustering and Supervised Classifier"IJISRET Volume 3, Special Issue 1, February 2014

34. Htet Thazin Tike Thein and Khin Mo Mo Tun "An Approach for Breast Cancer Diagnosis Classification Using Neural Network" Advanced Computing: An International Journal (ACIJ), Vol.6, No.1, January 2015

35. Haowen You and George Rumbe" Comparative Study of Classification Techniques on Breast Cancer FNA Biopsy Data", International Journal of Artificial Intelligence and Interactive Multimedia, Vol. 1, No 3,2010

36. L. Álvarez Menéndez, Francisco Javier de Cos Juez, Fernando Sánchez Lasheras, J. A. Álvarez Riesgo:"Artificial neural networks applied to cancer detection in a breast screening programme". Mathematical and Computer Modelling 52(7-8): 983-991 (2010). 